\title{
HUNIAN SOSIAL DENGAN PENDEKATAN GREEN ARCHITECTURE
}

\author{
Naganda Putra Margamu ${ }^{1)}$, Suryono Herlambang ${ }^{2)}$ \\ 1)Program Studi S1 Arsitektur, Fakultas Teknik, Universitas Tarumanagara, Nagandaitusaya@gmail.com \\ 2) Program Studi S1 PWK, Fakultas Teknik, Universitas Tarumanagara, Suryonoh@ft.untar.ac.id
}

Masuk: 04-07-2021, revisi: 15-08-2021, diterima untuk diterbitkan: 23-10-2021

\begin{abstract}
Abstrak
Rumah menjadi tempat untuk tinggal bagi para penghuni. Dimana penghuni harus merasakan tempat yang nyaman dan layak. Kurangnya ruang terbuka hijau di Jakarta menyebabkan polusi semakin meningkat. Kota Jakarta seharusnya menggunakan ruang terbuka hijau bagi warganya untuk menjadi lebih baik, tak terkecuali masyarakat kalangan bawah dimana mereka membutuhkan fasilitas fasilitas tersebut agar kehidupan mereka menjadi lebih layak dalam aspek sosial maupun kesehatan. Oleh karena itu proyek ini dilakukan untuk menyadarkan masyarakat pentingnya ruang terbuka hijau di jakarta serta membuat tempat yang layak bagi masyarakat kalangan bawah. Pada proyek ini menawarkan progam social housing dan juga ruang terbuka hijau bagi para penghuni maupun masyarakat sekitar. Dengan menggunakan metode perancangan stack yang bertujuan agar bangunan, tapak dan sekitarnya saling terhubung satu sama lain. Proyek ini juga menerapkan sistem green building yang dimana minimnya ruang hijau di jakarta. Pada metode perancangan ini menerapkan raiwater haversting, food production, dan penghijauan di setiap lantainya. Pada bagian penghuni terdapat pasar, warung, menjual tanaman hias, warteg dan foodcourt untuk pekerjaan para penghuni serta fasilitas fasilitas pada masyarakat sekitar seperti jogging track, taman bermain, taman dan sebagainya. Sehingga alam, penghuni, masyarakat tetap saling menyehatkan.
\end{abstract}

Kata kunci: Social Housing; Ruang Terbuka Hijau; Green Building

\begin{abstract}
House is a place to live for the residents should feel comfortable and live ini decent place. The lack of green open space in Jakarta causes pollution to increase. The city of jakarta should use green open spaces fot its citizens to better, including the lower class community where they need these facillities so that their lives become more decent in terms of social and health aspects. Therefore, this project is carried out to make the public aware of the importance of green open space in Jakarta and to make a suitable place for the lower class community. This project offers a social housing progam and green open space for residents and the surrounding community. By using stack design methods to make, the building, site, and surroundings connected. This project also implements a green building system where there is a lack of green space in jakara. In this design, the method applies rainwater haversting, food production, and greenery on each floor. In the residents section, there are markets, stalls, selling ornamental plants, water, and foodcourt for thr residents work and facilities for the surrounding community such as jogging tracks, playgorund, parks, and else. So that nature, residents, society will keep each other healthy.
\end{abstract}

Keywords: Social Housing; Open Green Spaces; Green Building

\section{PENDAHULUAN}

Permasalahan lingkungan hijau menjadi buah bibir pada akhir akhir ini. Dimana setiap tahun lahan penghijauan di jakarta menurun yang dimana target pada tahun 2030 harus mencapai $30 \%$ ruang terbuka hijau di jakarta, Namun pada tahun 2019 ruang terbuka hijau di jakarta hanya mencapai 14,9\% sedangkan pada tahun 2020 turun hingga mencapai 9,98\% dimana masih jauh dari target pemrov DKI Jakarta. Menurut World Health Organisation (WHO), 30\% bangunan gedung dunia mengalami masalah kualitas udara dalam ruangan. Kondisi kota di Indonesia yang umumnya berkembang pesat dan berfungsi sebagai pusat kegiatan yang dikarenakan tingginya angka 
penduduk. Namun kaum dari kalangan miskin, biasanya menyasar di pinggiran kota yang belum memliki fasilitas ruang kota yang lebih baik serta limbah - limbah yang bertumpuk di pinggiran kota dan polusi udara yang semakin meningkat. Sehingga semakin lama wilayah pemukiman kumuh semakin terlantar dan tidak layak huni.

Permukiman kumuh dapat timbul akibat permasalahan kesehatan dan ketidaknyamanan dikarenakan kualitas udara yang memburuk serta kurangnya ruang hijau di wilayah tersebut. Menyebabkan masyarakat berpenghasilan rendah memiliki lingkungan yang buruk bahkan ada yang rumahnya tidak layak dihuni. Salah satu cara meningkatkan kualitas lingkungan masyarakat dengan menyediakan ruang terbuka hijau bersama dengan masyarakatnya, dengan cara itu juga dapat menciptakan kualitas udara lebih bersih serta mengurangi dampak terserangnya penyakit. Pada lingkungan perumahan tersebut juga terdapat sarana dan prasana bagi anak-anak serta fasilitasfasilitas yang menunjukan aktivitas sosial bagi masyarakat tersebut.

Dalam hal ini bangunan juga di buat dengan konsep Green Architecture. Dimana dibuat untuk meminimalisir berbagai bahaya pada kesehatan manusia dan lingkungan. Konsep ini juga memiliki manfaat lebih baik untuk pemukiman kumuh dimana bangunan ini lebih tahan lama, hemat energi, lebih mudah dirawat, nyaman, serta yang paling utama lebih sehat untuk masyarakat yang tinggal disana. Dimana konsep green architecture memberi hal baik pada masalah lingkungan khususnya pada pemanasan global yang selalu meningkat. Sehingga konsep green architecture cocok dengan masalah tersebut. Dalam hal ini arsitektur memerlukan konsep green architecture dan lokalitas dalam mewadahi tempat tinggal yang layak bagi masyarakat berpenghasilan rendah dengan cara menyatukan hubungan luar (RTH) dan hunian sosial yang bertujuan untuk meningkatkan mutu lingkungan serta kualitas dalam bangunan tersebut.

Penelitian ini bertujuan untuk mengurangi dampak negatif dari kurangnya lahan hijau di jakarta serta mewadahi tempat tinggal yang layak bagi masyarakat rendah. Di harapkan kedepannya dapat menghasilkan generasi yang peduli terhadap lingkungan serta masyarakat pinggiran.

\section{KAJIAN LITERATUR}

\section{Pengertian Ekologi}

Ekologi berasal dari bahasa Yunani "oikos" dan "Logos". Oikos berati rumah tangga atau cara bertempat tinngal, dan logos berati ilmu atau bersifat ilmiah. Ekologi didefinisikan sebagai ilmu yang mempelajari tentang hubungan timbal balik antara makhluk hidup dengan lingkungan di sekitarnya (Frick, 2007).

\section{Pengertian Arsitektur Ekologi}

Arsitektur ekologi adalah suatu konsep ekologi arsitektur yang bertujuan pada keseimbangan alam serta bangunan yang berkelanjutan dalam efesiensi energi dan sumber daya alam. arsitektur ekologi ini tentang lingkungan dan bangunan yang sering disebut juga green building dimana konsep tersebut juga berkaitan dengan arsitektur berkelanjutan (Sukawi, 2008). Arsitektur berkelanjutan yang ekologis dapat dikenali dengan cara sebagai berikut (Frick, 2007) :

a. Tidak menghabiskan bahan lebih cepat dari pada tumbunya kembali bahan tersebut oleh alam.

b. Menggunakan energi terbarukan secara optimal.

c. Menghasilkan sampah yang dapat dimanfaatkan sebagai sumber bahan baru.

d.

Arsitektur ekologis mencerminkan adanya perhatian terhadap lingkungan alam dan sumber alam yang terbatas. Secara umum, arsitektur ekologis dapat diartikan sebagai penciptaan lingkungan yang lebih sedikit mengkonsumsi dan lebih banyak menghasilkan kekayaan alam. Arsitektur tidak dapat mengelak dari tindakan peruskan lingkungan. Namun demikian, arsitektur ekologis dapat 
digambarkan sebagai arsitektur yang hendak merusak lingkungan sesedikit mungkin. Untuk mencapai kondisi tersebut, desain diolah dengan cara memperhatikan aspek iklim, rantai bahan, dan masa pakai material bangunan. Prinsip utama arsitektur ekologis adalah menghasilan keselarasan antara manusia dengan lingkungan adanya.

\section{Sifat Arsitektur Ekologis}

Arsitektur ekologis bersifat holistis (berkeseluruhan). Arsitektur ekologis mengandung bagian-bagian dari (Frick, 2007):

1. Holistis : berhubungan dengan sistem keseluruhan, sebagai suatu kesatuan yang lebih penting dari pada sekedar kumpulan bagian.

2. Memanfaatkan pengalaman manusia (tradisi dalam pembangunan), dan pengalaman lingkungan alam terhadap manusia.

3. Pembangunan sebagai proses dan bukan sebagai kenyataan tertentu yang statis.

4. Kerja sama manusia dengan alam sekitarnya demi keselamatan kedua belah pihak.

\section{Beyond Ecology}

Beyond ecology - 'melampaui ecclogy' adalah sebuah kondisi ekosistem dengan kondisi formasi sosialnya yang mengalami kondisi kecepatan dan percepatan. Pada titik ini, kecepatan menjadi jantung dunia keseharian dan ekosistem disekitar kita yang mengalami 'pemadatan waktu' (time compression) sebagai konsekwensi dari percepatan kehidupan (Sutanto, 2021).

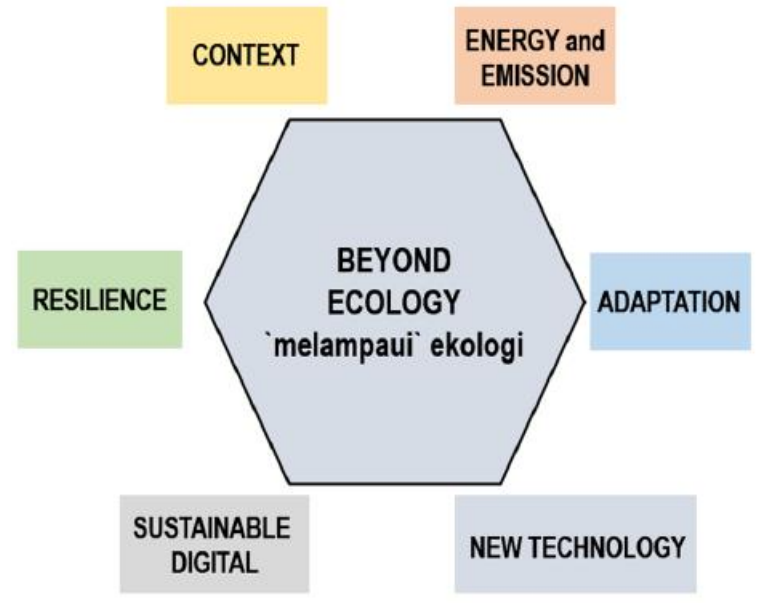

Gambar1. Beyond Ecology

(Sumber: (Sutanto, 2021))

Parameter dalam arsitektur menuju 'Beyond Ecology' (Sutanto, 2021):

1. Energy and Emission adalah kemampuan untuk menerapkan zero $\mathrm{CO} 2$ emission dalam pengoperasionalan bangunan dan meminimalisir efek karbon dalm material dan kontruksi.

2. Adaptation adalah kemampuan untuk melakukan riset dan desain yang berkaitan dengan berbagai dampak seperti naiknya suhu bumi, naiknya pemukiman laut, kekeringan, banjir, kelangkaan pangan, perubahan populasi.

3. Resilence adalah kemampuan untuk membangun kelanjutan hunian dan pemulihan cepat setelah kejadian guncangan, bencana alam, gangguan listrik atau iklim.

4. Sustainable Digital adalah kemampuan untuk melihat data-data lingkungan sebagai Big Data dalam menentukan taktik dan strategi dalam membangun kualitas spasial.

5. New Technology adalah kemampuan memanfaatkan teknologi terbaru untuk meningkatkan kualitas dari terapan ruang - kontruksi dan progam bangunan.

6. Context adalah kemampuan dalam melihat posisi 'tempat' dalam hubungan dengan lingkungan (flora-fauna, biotic-abiotic) dimana sebuah konfigurasi keruangan yang akan ditempatkan. 


\section{Green Architecture}

Green Achitecture merupakan konsep arsitektur yang mengurangi pengaruh buruk terhadap alam maupun manusia dengan cara memanfaatkan sumber energi dan sumber daya alam secara efisien (Sudarwani, 2012). Green juga dimaksudkan pada pengurangan energi seperti listrik dan air. Dengan sumber listrik dari sinar matahari (solar panel) serta air dari yang sudah di pake lalu di bersihkan untuk di pakai ulang (rainwater harvesting).

\section{Green Building}

Green building adalah konsep untuk 'bangunan berkelanjutan' dan mempunyai syarat tertentu, yaitu lokasi, sistim perencanaan dan perancangan, renovasi dan pengoperasian, yang menganut prinsip hemat enrgi serta harus berdampak positif bagi lingkungan, ekonomi dan sosial (Sudarwani, 2012). Cara mengurangi dampak pada lingkungan terhadap kesehatan manusia dan lingkungan alam dengan cara (Sudarwani, 2012):

a. Efisien menggunakan energi, air, dan sumber daya lainnya. Dirancang dengan biaya lebih sedikit untuk mengoperasikan dan memiliki kinerja energi yang sangat baik.

b. Efisiensi energi dapat berupa efisiensi tinggi, jendela dan isolasi di dinding

c. Melindungi kesehatan penghuni dan meningkatkan produktivitas karyawan.

d. Mengurangi sampah, polusi dan degradasi lingkungan.

e. Bangunan alami, yang biasanya pada skala yang lebih kecil dan cenderung untuk fokus pada penggunaan bahan-bahan alami yang tersedia secara lokal.

f. Bangunan hijau tidak secara khusus menangani masalah perkuatan rumah yang ada.

g. Mengurangi dampak lingkungan : Praktek green building bertujuan untuk mengurangi dampak lingkungan dari bangunan.

\section{Rumah Susun}

Rumah susun pada dasarnya merupakan apartemen versi murah. Rumah susun adalah sekelompok rumah yang di bangun dalam suatu lingkungan secara fungsional dalam arah horisontal maupun vertikal dan digunakan secara satuan yang masing masing dapat dimiliki secara terpisah(SNI 03-70132004). Rumah susun sederhana biasa terdiri dari 4 lantai yang berisi sebagai tempat penghuni serta mewadahi aktivitas penghuni dengan luas minimal $18 \mathrm{~m} 2$ sampai 36m2(SNI 03-7013-2004).

Banyaknya unit pada bangunan menjadi satu lingkungan perumahan yang berbeda dengan bangunan rumah di atas tanah. Dengan adanya banyaknya unit pada satu bangunan akibatnya banyak kebiasaan baru dalam penyesuaian diri. Sehingga kenyamanan, keamanan dan kesehatan menjadi faktor pendukung dalam bersosialisasi antar warga. Faktor yang harus memenuhi kebutuhan rumah susun yaitu (SNI 03-7013-2004).

a. Memberi rasa aman, ketenangan hidup, kenyamanan pada budaya setempat.

b. Merubah kebiasaan yang tidak dilakukan di rumah susun.

c. Mengurangi menggunakan fasilitas umum untuk kepentingan pribadi.

d. Menunjang fasilitas fasilitas penghuni yang paling pokok maupun yang sudah ada pada lingkungan tersebut.

e. Menampung fungsi fungsi yang berkaitan dengan aspek aspek ekonomi dan sosial budaya setempat.

\section{METODE}

\section{Stack dan Lokalitas}

Metode desain dalam perancangan arsitektur dapat dilakukan dengan banyak pendekatan. Dimana pendekatan tersebut dapat digunakan untuk mengatur ruang, material yang digunakan, estetika bangunan dan sebagainya. Salah satu pendekatan yang akan dilakukan melalui pendekatan Lokalitas 
dan Stack. Dimana pendekatan ini lebih mementingkan lingkungan sekitar juga dengan aktivitas pengguna agar lebih nyaman.

Lokalitas adalah sebuah "gerakan" yang memperjuangkan identitas kelokalan ditengah arus globalisasi. Lokalitas bergerak dan hidup dalam "serangan" modernitas dan "gelombang" globalisasi, yang akhirnya membuat "terpinggirkan". Namun dalam perkembangannya, ketika dunia menjadi begitu modern dan universal, kerinduan akan nilai-nilai kelokalan masih terus digali dan dicari serta dianggap sebagai kekuatan keruangan yang memiliki aura identitas dan karakter sebuah tempat.

Dengan pemikiran Lewis Mumford, Liane Lefaivre mengungkapkan ada lima poin penting dalam memandang nilai lokalitas:

a. Lokalitas bukan hanya terpaku dari kebesaran atau nilai absolut dari sejarah

b. Lokalitas adalah tentang bagaimana melihat bahwa sebuah tempat memiliki sentuhan personal, untuk sebuah keindahan yang tidak terduga.

c. Lokalitas dalam perkembangannya harus memanfaatkan teknologi yang berkelanjutan, dan ini menjadi penting dalam membangun sebuah tradisi baru.

d. Lokalitas harus memberikan kegunaan terhadap penggunanya, modifikasi terhadap lokalitas harus dibuat bukan hanya sekedar memenuhi kebutuhan.

e. Globalitas dan Lokalitas bukanlah sesuatu yang harus dipertentangkan tetapi mereka saling melengkapi.

Metode desain dengan menggunakan beyond urban ecology : stack / Benjamin bratton.

User

\begin{tabular}{c}
\hline $\begin{array}{c}\text { Aktivitas penghuni / pengguna pada kawasan sebagai dasar menentukan progam. } \\
\text { Interface }\end{array}$ \\
\hline Teknologi yang digunakan untuk mempermudah penghuni \\
Adress \\
Kriteria tapak terhadap lingkungan \\
City \\
\hline Akses tapak terhadap transportasi umum. \\
Cloud \\
\hline Konsep yang digunakan berdasarkan isu serta progam yang di ambil untuk penghuni. \\
Earth
\end{tabular}

Kondisi iklim pada tapak serta kondisi topografi terhadap fungsi yang di ambil.

\section{DISKUSI DAN HASIL}

Hasil analisis di rangkai dalam satu kesatuan dengan menggunakan metode stack dari Bejamin Bratton:

\section{User}

Aktivitas penghuni masyarakat sekitar serta yang tinggal pada area tapak. Aktivitas mereka dapat di lihat mereka melakukan kerja bakti, merawat tanaman, membuka warung, berbincang bincang antar warga, bersepeda dll. Dimana itu bisa sebagai acuan progam untuk para penghuni yang tinggal maupun di sekitarnya. 


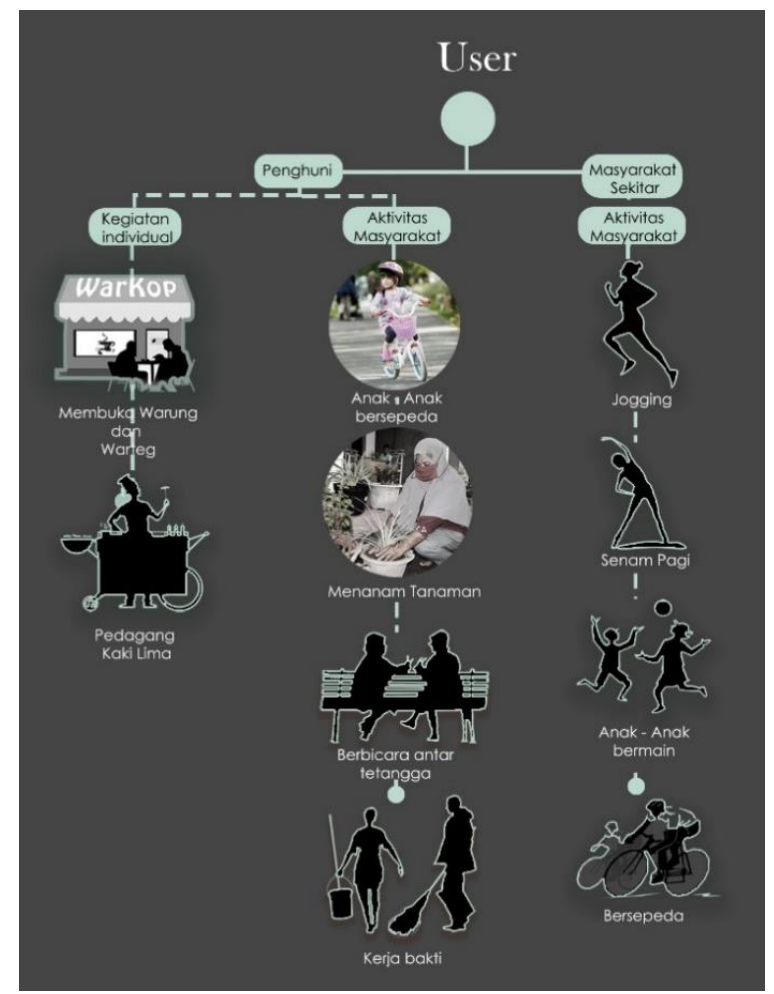

Gambar2. User

(Sumber : (Penulis, 2021))

\section{Interface}

Pada proyek social housing ini bertujuan untuk membuat masyarakat memiliki kehidupan yang layak serta memiliki ruang terbuka hijau yang cukup di Jakarta untuk memenuhi kebutuhan pemerintah pada tahun 2030 dimana ruang terbuka hijau harus memenuhi 30\% di jakarta. Dengan menggunakan teknologi green building low cost tech serta membuat bangunan yang sustainable.

\section{Kriteria yang di terapkan pada bangunan}

Pada gambar 3, terdapat 3 faktor penting yaitu efisiensi energi dan air, efisiensi bahan serta peningkatan mutu lingkungan. Dimana material yang digunakan material lokal seperti kayu, bata, beton sebagai tempat lokalitasnya penduduk. Pada area tapak juga di berikan tempat produksi tanaman berupa hidroponik maupun tidak. Tujuannya agar penghuni dapat menjual kembali makanan tersebut atau di konsumsi secara pribadi dan juga sebagai penghijauan. Pada bagian atap di berikan solar panel sehingga kebutuhan energi listrik bangunan lebih efisien. Lalu rainwater harvesting diletakkan di area tempat produksi tanaman agar langsung di sirami. Pada penggunaan rainwater harvesting menggunakan material beton serta di lapisi kayu untuk memperindah rainwater harvesting tersebut.

Pada area public space diberikan ruang hijau untuk meningkatkan mutu lingkungan seperti pepohonan pada jalur pedestrian, rain garden sebagai memperindah taman juga sebagai penyerapan air supaya tidak banjir, permeable paveament sebgai jalur pada tapak serta di gunakan sebagai penyerapan air hujan, dan juga bioswale yang digunakan untuk memperindah tapak juga di gunakan sebagai peghalang polusi kendaraan dan juga penyerapan air hujan. 


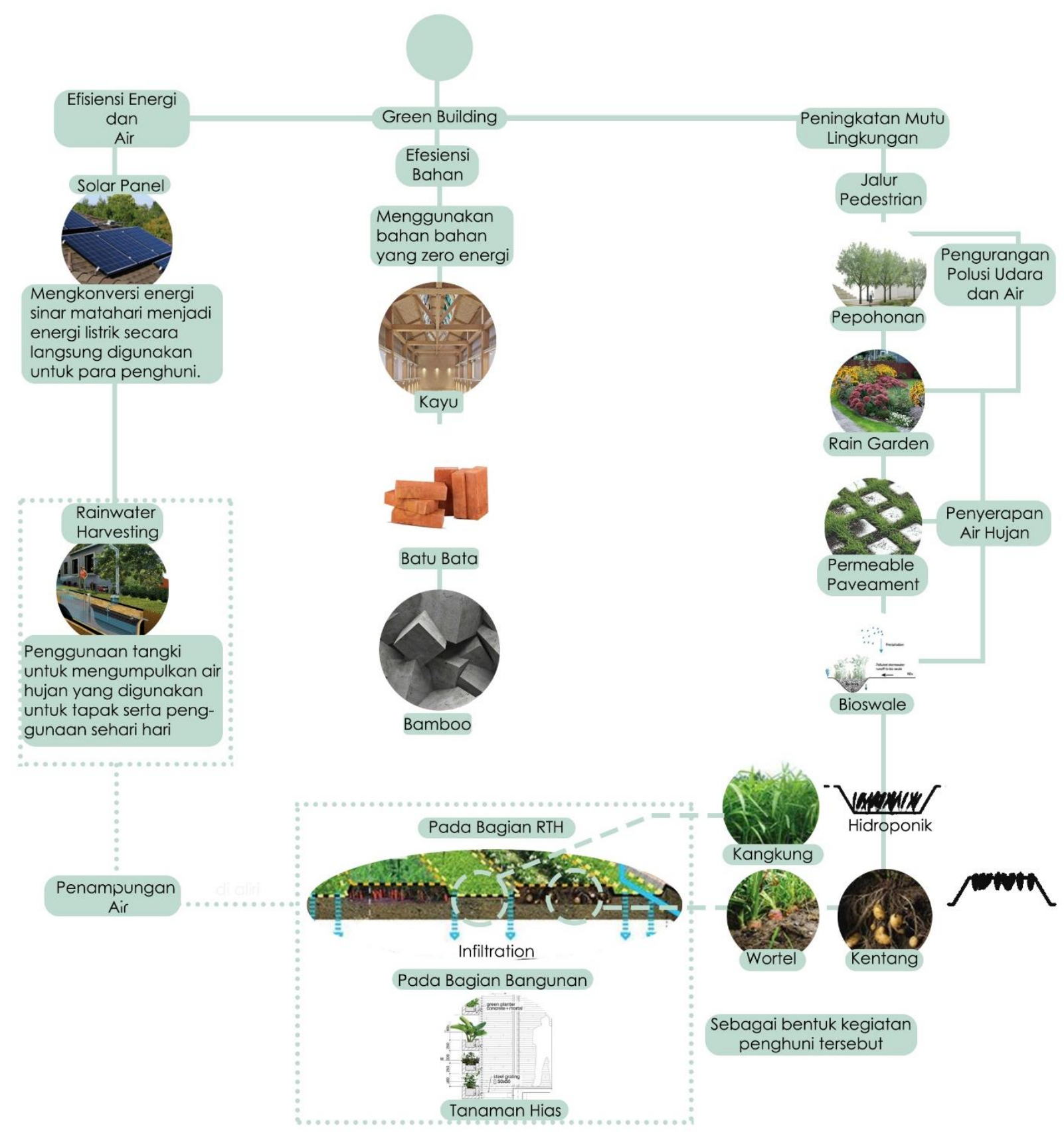

Gambar 3. Green Building

(Sumber: (Penulis,2021))

Pada area public space diberikan ruang hijau untuk meningkatkan mutu lingkungan seperti pepohonan pada jalur pedestrian, rain garden sebagai memperindah taman juga sebagai penyerapan air supaya tidak banjir, permeable paveament sebgai jalur pada tapak serta di gunakan sebagai penyerapan air hujan, dan juga bioswale yang digunakan untuk memperindah tapak juga di gunakan sebagai peghalang polusi kendaraan dan juga penyerapan air hujan.

\section{Address \& City}

Tapak yang dipilih berupa daerah dengan kebutuhan ruang terbuka hijau yang minim berada di jakarta utara dan juga masyarakat berpenghasilan rendah. 
1. Data Tapak:

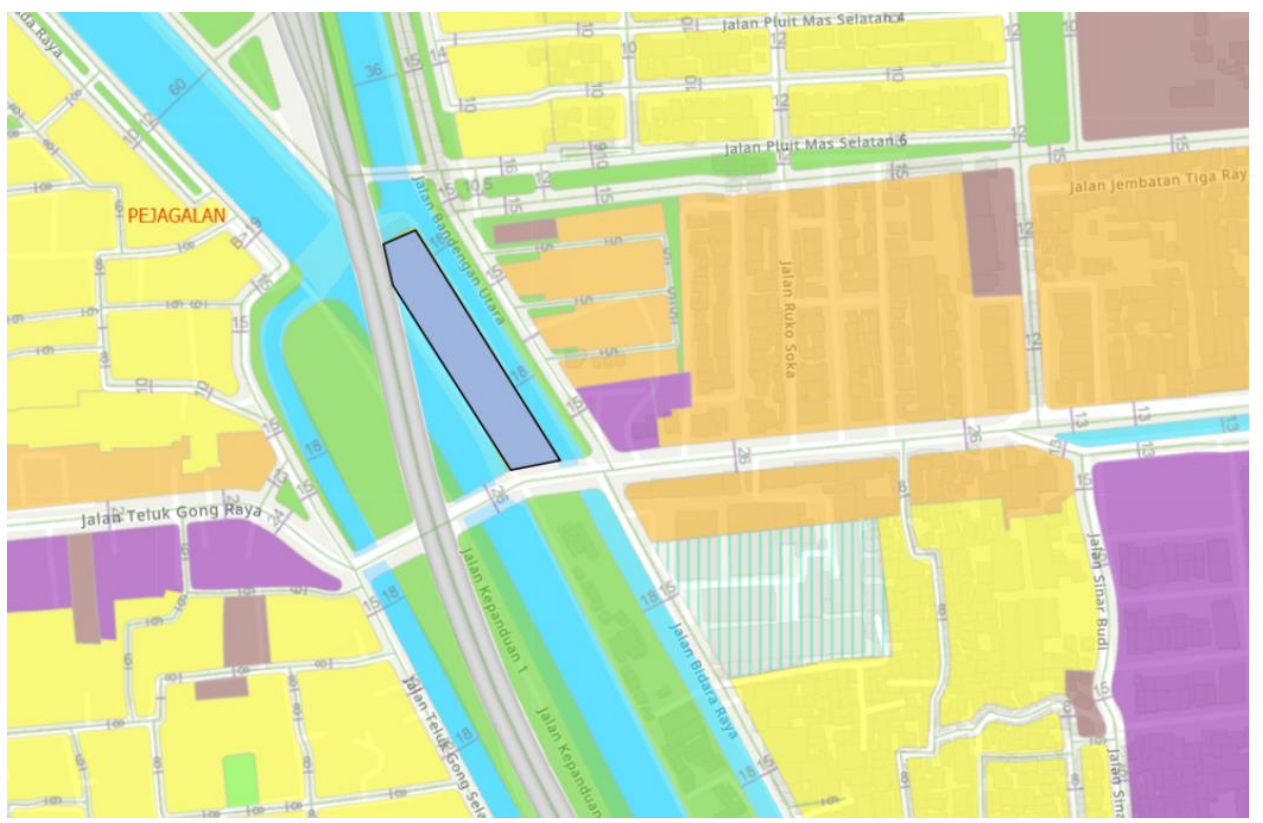

Gambar4. Lokasi Tapak

(Sumber :(Jakarta Satu,2021))

Tapak terpilih berada di Jl. Terusan Bandengan di Kacamatan Penjaringan.

Zona Peruntukan: zona hijau

Dimana tapak ini saya ingin membuat dengan pemukiman yang berada di sana tidak di gusur melainkan di bangun ulang dengan:
Luas Tapak : :8400 m2
KDB $\quad: 30 \%$
$\mathrm{KB} \quad: 4$
KLB
$: 1,2$
$\mathrm{KDH} \quad: 70$

Dimana tapak ini dibuat untuk menyambungkan antara RPTRA KALIJODO dengan hutan Penjaringan.

\section{Permasalahan dan Potensi Tapak}

Kalijodo merupakan salah satu yang terletak di kecamatan penjaringan, kota jakarta utara, provinsi DKI Jakarta. Dimana penduduk kelurahan ini berjumlah 90.504 jiwa, dengan kepadatan penduduk $28.020 \mathrm{jiwa} / \mathrm{km} 2$.

Kacamatan Penjaringan banyak sekali pemukiman yang layak. Namun banyak pemukiman kumuh di sekitarnya yang berada di pinggiran yang tidak terawat (tidak layak lagi). Pada kondisi ini warga yang lewat di pemukiman kumuh tersebut tidak ada yang peduli satu pun. Disekitar tapak tersebut terdapat pedagang kaki lima yang banyak di pinggiran pemukiman kumuh tersebut namun tidak tertata dengan rapih dan juga banyak sampah. Sehingga kesehatan mereka bisa terancam setiap saat. Kondisi tapak disana saat ini:

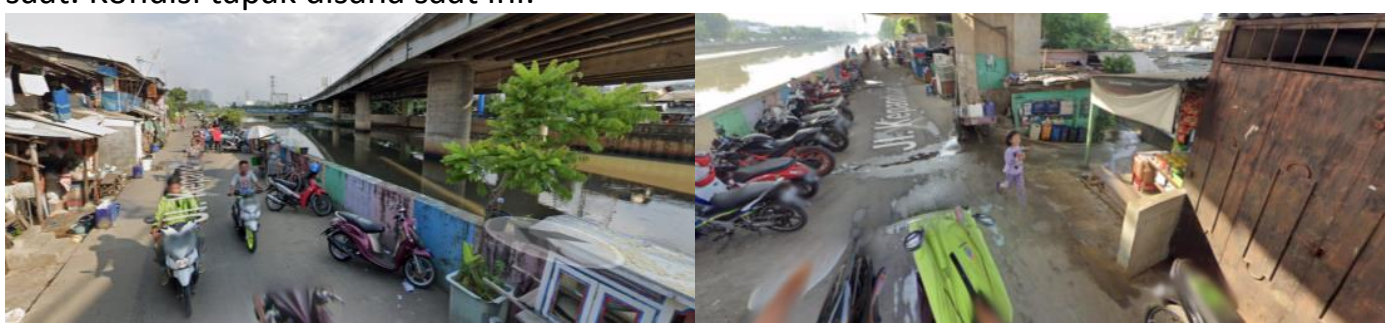

Gambar5. Pemukiman Kumuh di Kecamatan Penjaringan

(Sumber: (Google Maps, 2021)) 
Pada tapak selalu ada ancaman, kekuatan, kelemahan, serta potensi yang digunakan untuk mengembangkan design yaitu pada contoh di gambar bagian bawah tersebut.

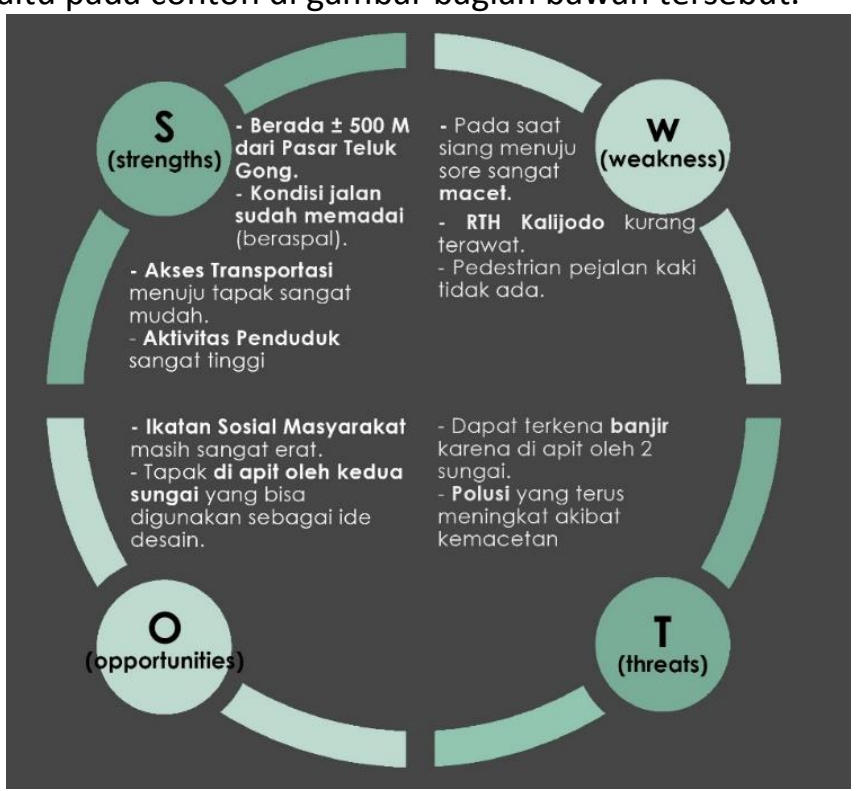

Gambar6. Analisis SWOT

(Sumber: (Penulis,2021))

Sasaran target pada tapak ini yaitu: pada area pasar dimana sebagai wadah masyarakat untuk membeli makanan atau menjual makanan, pada area sungai juga sebagai tempat view pada tapak untuk masa yang akan datang untuk para penghuni serta pada area perumahan dimana masyarakat harus terjangkau ke tapak untuk aktivitas mereka.

\section{Kondisi Kawasan \& Analisis Sekitar Tapak}

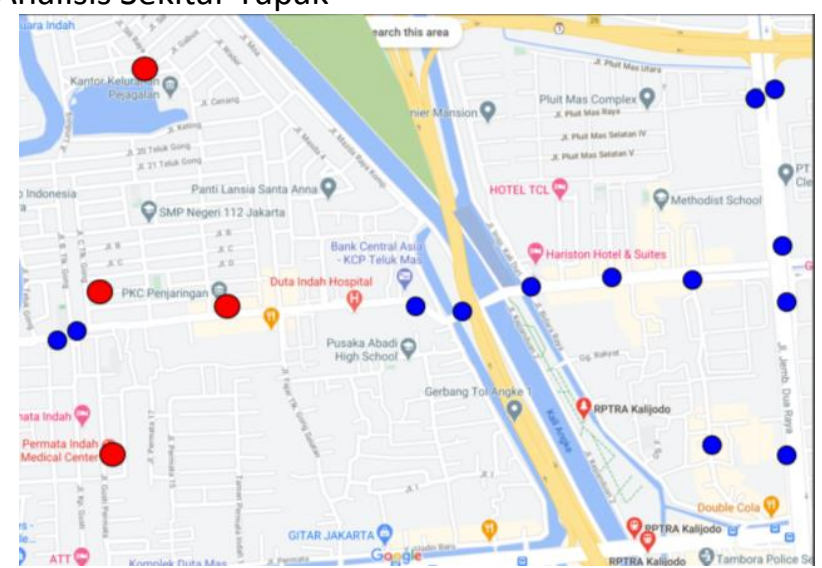

Gambar7. Peta Sekitar di Jl. Terusan Bandengan di kacamatan Penjaringan

(Sumber :(Google Maps,2021))

Keterangan

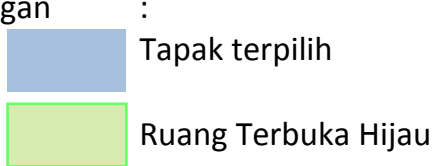

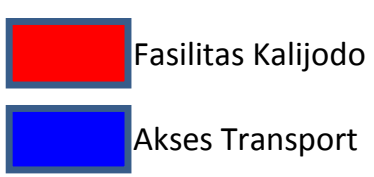

Pemukimanan pada kawasan Kec. Penjaringan di dominasi oleh pemukiman. Kebanyakan pemukiman disana pemukiman kecil dan juga sedang. Sisanya untuk fasilitas publik seperti puskesmas, taman kota, public space dll. 


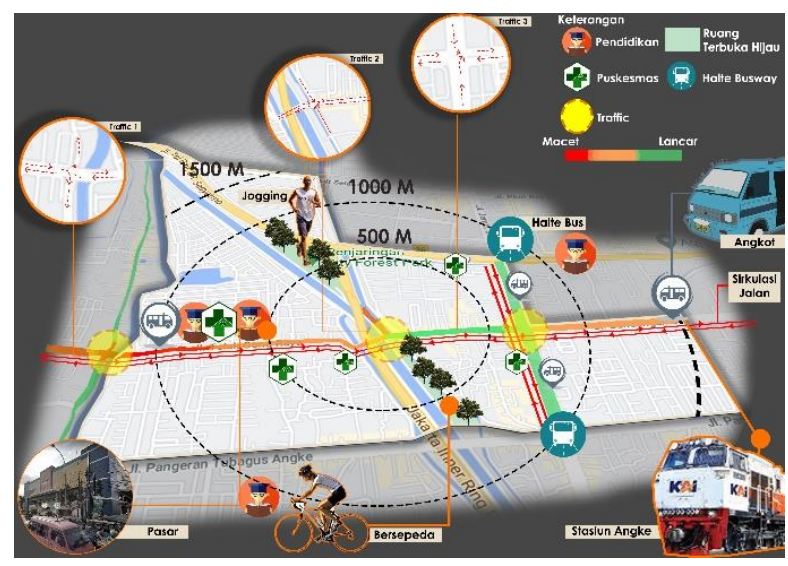

Gambar8. Analisis Radius Tapak

(Sumber :(Penulis,2021))

Pada sekitar tapak Kalijodo terdapat fasilitas fasilitas untuk kegiatan penghuni yaitu pada area 500 meter terdapat Puskesmas, Hutan penjaringan, RPTRA KALIJODO. Pada area $1 \mathrm{~km}$ terdapat angkot, Sekolah SD SMP, puskesmas, Serta pasar untuk pada penghuni dan anak anaknya. Pada 1,5 km terdapat Stasiun Angke Sekolah SMA di sekitar tapak. Serta ada tempat ibadah seperti vihara, gereja dam juga musholla/ masjid.. Akses publik ke tapak juga baik dimana ada angkutan umum yang langsung menuju tapak.

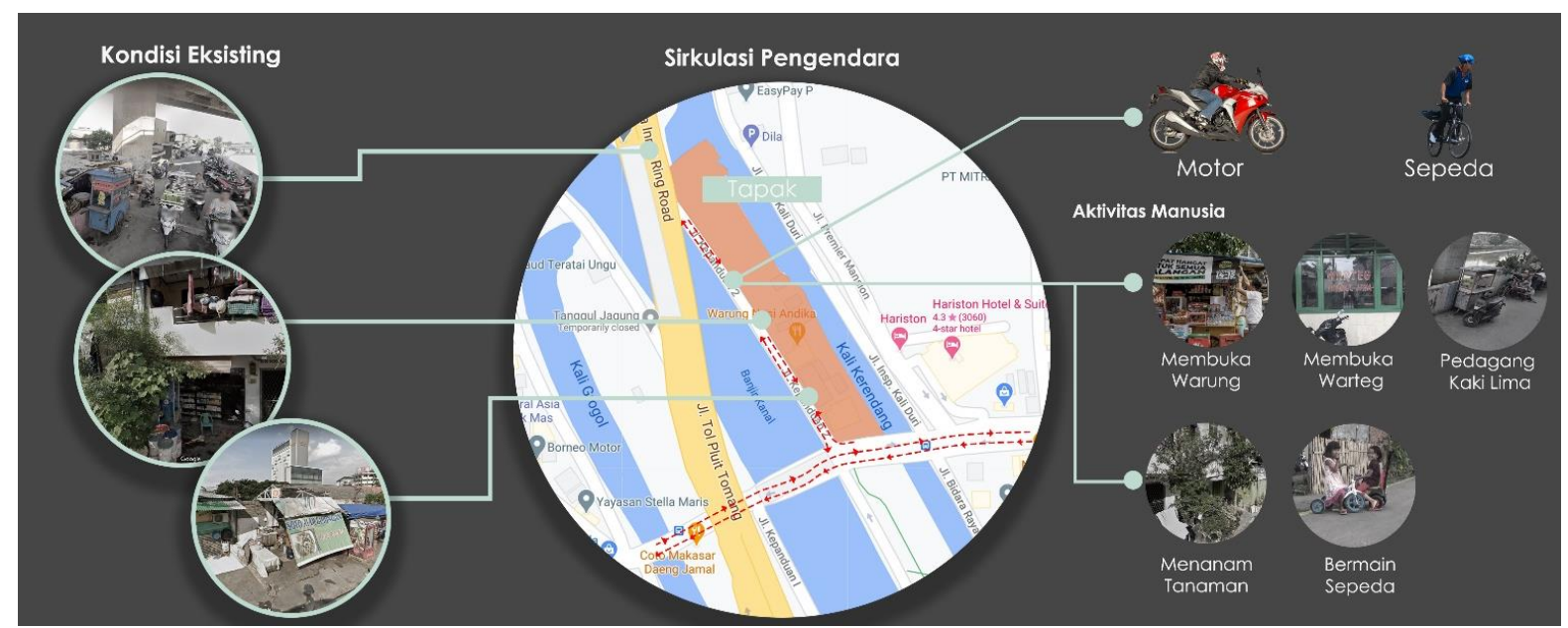

Gambar 9. Analisis Aktivitas Sekitar Tapak

(Sumber:(Penulis,2021))

Pada area sekitar tapak terdapat motor serta sepeda yang berjalan di area sekitar tapak, serta banyak aktivitas aktivitas masyarakat yang dilakukan di sekitar tapak seperti: membuka warung, warteg, PKL dan juga anak anak bermain sekitar tapak serta menanam tanaman.

\section{Cloud}

Progam yang akan di ambil dari hasil analisis kawasan yaitu:

1. Pada area outdoor social housing 


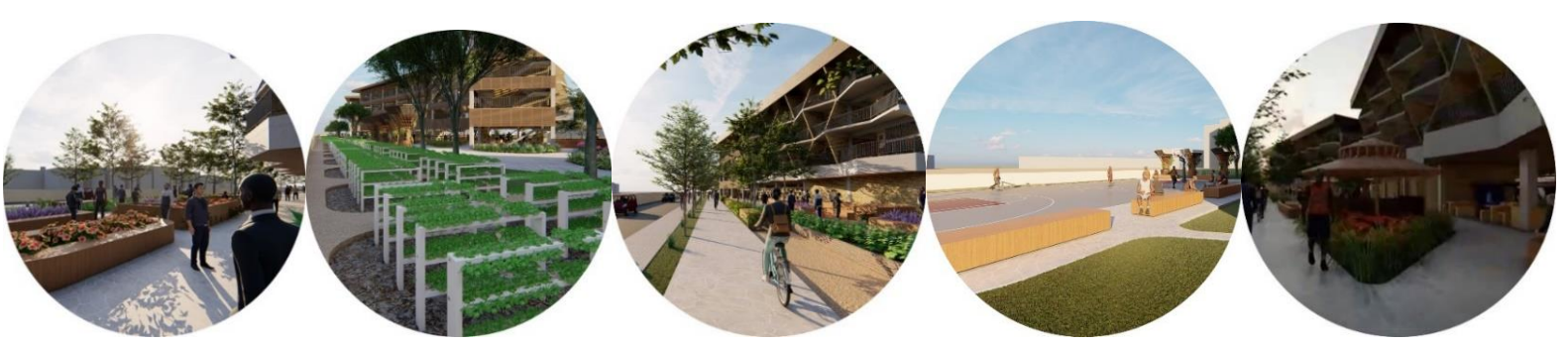

Gambar 10. Progam Outdoor

(Sumber :(Penulis,2021))

1. Taman sebagai sarana anak, masyarakat, penghuni bermain.

2. Hidroponik untuk para warganya menghasilkan makanan sendiri lalu di jualkan serta konsumsi pribadi.

3. Trek sepeda di mana pada area tersebut banyak orang yang gemar sepeda.

4. Lapangan dimana rata rata usia remaja disana gemar berolahraga.

5. Pondok - pondok sebagai wadah nongkrong-nongkrong antar warga sebagai wadah sosial.

\section{Pada area indoor social housing}

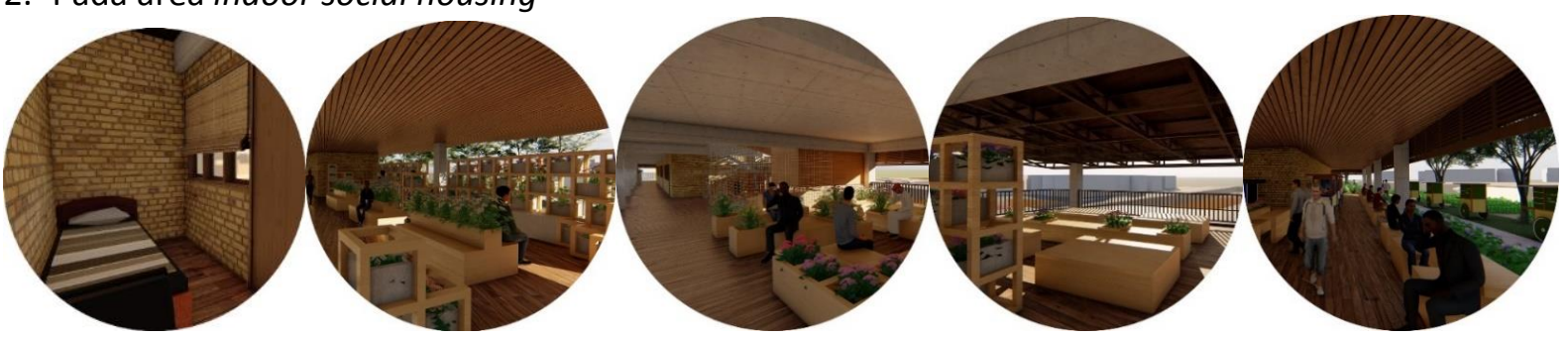

Gambar 11. Progam Indoor

(Sumber:(Penulis,2021))

1. Kamar tidur untuk mereka tinggal dimana terbagi menjadi 2 yaitu tipe 42 serta tipe 21 untuk para penghuni dan juga lantai 2 \& 3 lebih dominan tipe 42 dimana memudahkan bagi manula untuk naik.

2. Toko taneman dimana tidak hanya digunakan sebagai hobbi melainkan sarana tempat untuk menjual taneman tersebut.

3. Communal space untuk para penghuni dikarenakan mereka sangat gemar nongkrong antar warga.

4. Playground sebagai wadah anak anak bersosialisasi satu sama lain mau di luar tapak maupun antar penghuni.

5. Foodcourt PKL dan pasar untuk perekonomian mereka sehari - hari dimana sebagai besar mereka bekerja di warung, pedagang kaki lima, warteg dll.

Konsep bangunan diterapkan dalam area tapak dan massa bangunan pada sosial housing khususnya kamar harus memperhatikan orientasi matahari agar penghuni merasa nyaman di dalem ruangan maupun di luar ruangan. 


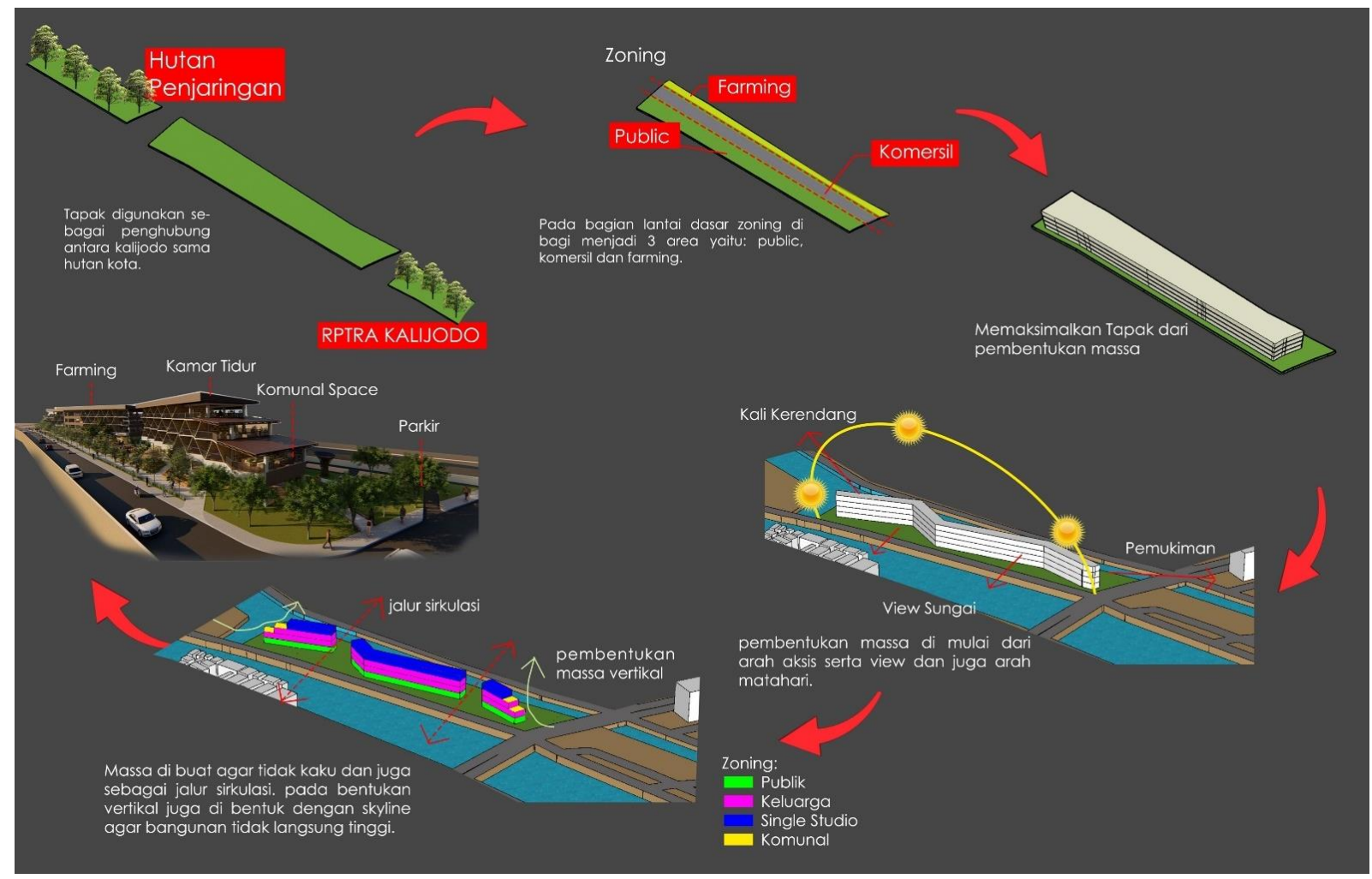

Gambar 12. Transformasi Massa

(Sumber :(Penulis, 2021))

Massa di bagi 3 zoning lantai dasar yaitu: publik, komersial, serta farming. Pada bagian vertikal juga dibagi 3 zoning lantai dasar publik, lantai 2-3 untuk keluarga, serta lantai teratas untuk single studio. Agar bagi para orang tua masih tetap nyaman untuk tinggal di sana. Pada bagian RTH diberikan kanopi pohon terhadapt pedestrian, rain garden pada area taman dan juga tapak, serta bioswale di pinggiran tapak agar polusi udara tetap sehat sehingga penghuni tetap nyaman. RTH juga di buat area panggung, tempat playground, ruang komunal, tempat olahraga, jogging track, track sepeda serta pondok pondok yang digunakan untuk memenuhi kebutuhan penghuni serta masyarakat sekitar yang ingin menggunakan public space tersebut.

Pada bagian bangunan di setiap lantai diberikan tanaman agar udara menjadi sejuk serta kebutuhan penghuni yang di karenakan gemar terhadap taneman. Pada bagian kamar diberikan cross ventilation dengan memakai krepyak untuk diterapkan dalam lokalitas serta juga digunakan sebagai tempat cahaya dan udara tetap masuk kedalam banguanan.

Pada balcon kamar juga dibuat miring untuk memaikan orientasi matahari terhadap kamar serta sebagai wadah view ke sungai dimasa depan semisal sungai sudah bersih dimasa depan. Pada bagian balcon juga diberikan tanaman yang bertujuan sebagai penyejuk ruangan serta kegemaran mereka terhadap tanaman tersebut. Pada bagian lantai dasar juga diberikan banyak pepohonan untuk memenuhi kebutuhan penghijauan di jakarta sehingga bangunan maupun lingkungan tetap sehat dan harmonis terdapat masyakarat maupun penghuni yang datang.

\section{Earth}

Kondisi tapak datar tidak berkontur, mungkin bisa terjadi banjir, memiliki iklim yang tropis dengan menggunakan prinsip arsitektur tropis dan juga lokalitas dengan menggunakan bahan lokal disana seperti kayu, bata dll. 


\section{KESIMPULAN DAN SARAN}

\section{Kesimpulan}

Proyek ini dilakukan dengan isu "Kurangnya ruang terbuka hijau di jakarta serta kurangnya tempat tinggal yang layak untuk masyarakat pinggiran". Dimana pada area ruang terbuka hijau di Jakarta Utara menurut data merupakan yang paling sedikit sehingga harus melakukan perubahan. Sehingga proyek ini di buat di jakarta utara beserta masyarakat pinggiran yang tempat tinggalnya sudah tidak layak lagi yang di ubah menjadi hunian sosial. Pada tapak tersebut menerapkan sistem green building pada bangunan agar bangunan menjadi efisiensi energi. Bertujuan untuk para penghuni menjadi lebih baik serta bangunan menjadi lebih sehat seperti solar panel dan rainwater haversting. Khususnya berkaitan dengan kelestarian alam serta kesehatan penghuni. Pada hunian sosial ini juga tetap harus memenuhi aspek aspek sosial dan ekonomi dimana membuat ruang ruang produktif pada area bawah sebagai aspek ekonomi mereka serta fasilitas fasilitas yang memenuhi kebutuhan mereka seperti: foodcourt yang berisikan PKL, warung, warteg, toko taneman hias, ruang komunal, produksi makanan dengan menggunakan sistem rainwater harvesting yang dapat digunakan kembali ketika air tersedia, serta taman yang berisikan jogging track, track sepeda, taman bermain dll untuk memenuhi kebutuhan RTH di jakarta. Pada area bangunan juga diberikan taneman sebagai penghijuan serta area kamar diberikan sinar matahari yang cukup dan cross ventilation yang baik agar penghuni tetep merasa aman dan nyaman.

\section{Saran}

Perancangan dilakukan pada saat pandemi sehingga diperlukannya studi lanjutan terhadap aktivitas masyarakat setempat serta merasakan secara langsung tempat tersebut. Sehingga dapat meningkatkan kualitas progam serta kebutuhan masyarakat setempat yang lebih nyata.

\section{REFERENSI}

03-7013, SNI. (2004). Tata Cara Perencanaan Fasilitas Lingkungan Rumah Susun Sederhana.

Frick, H. (2007). Dasar-dasar Arsitektur Ekologis. Yogyakarta: Kanisius.

Indeks Potensi Kerawanan Sosial Provinsi DKI Jakarta. (2019). Retrieved from Statistik jakarta: http://statistik.jakarta.go.id/media/2020/01/IPKS-2019-30122019.pdf

Lia Andriana, A. M. (2017). Relevansi Aspek Kemiskinan dan Fisik Lingkungan Kumuh Pada Penentuan Lokasi Penerima Progam KOTAKU. Pengembangan Kota, 139.

Soemarwoto, O. (1989). Ekologi Lingkungan Hidup dan Pembangunan. Jakarta: Djambatan.

Sudarwani, M. M. (2012). Penerapan Green Architecture dan Green Building Sebagai Upaya Pencapaian Sustainable Architecture.

Sukawi, S. (2008). EKOLOGI ARSITEKTUR MENUJU PERANCANGAN ARSITEKTUR HEMAT ENERGI DAN BERKELANJUTAN.

Sutanto, A. (2021). Dromos Oikos: Notes On The Fifth Ecology.

Syahadat, R. M. (2017). Ruang Terbuka Hijau dan Permasalahan Kesehatan Perkotaan Studi Kasus di Provinsi DKI Jakarta. Arsitktur Lansekap, 188. 
